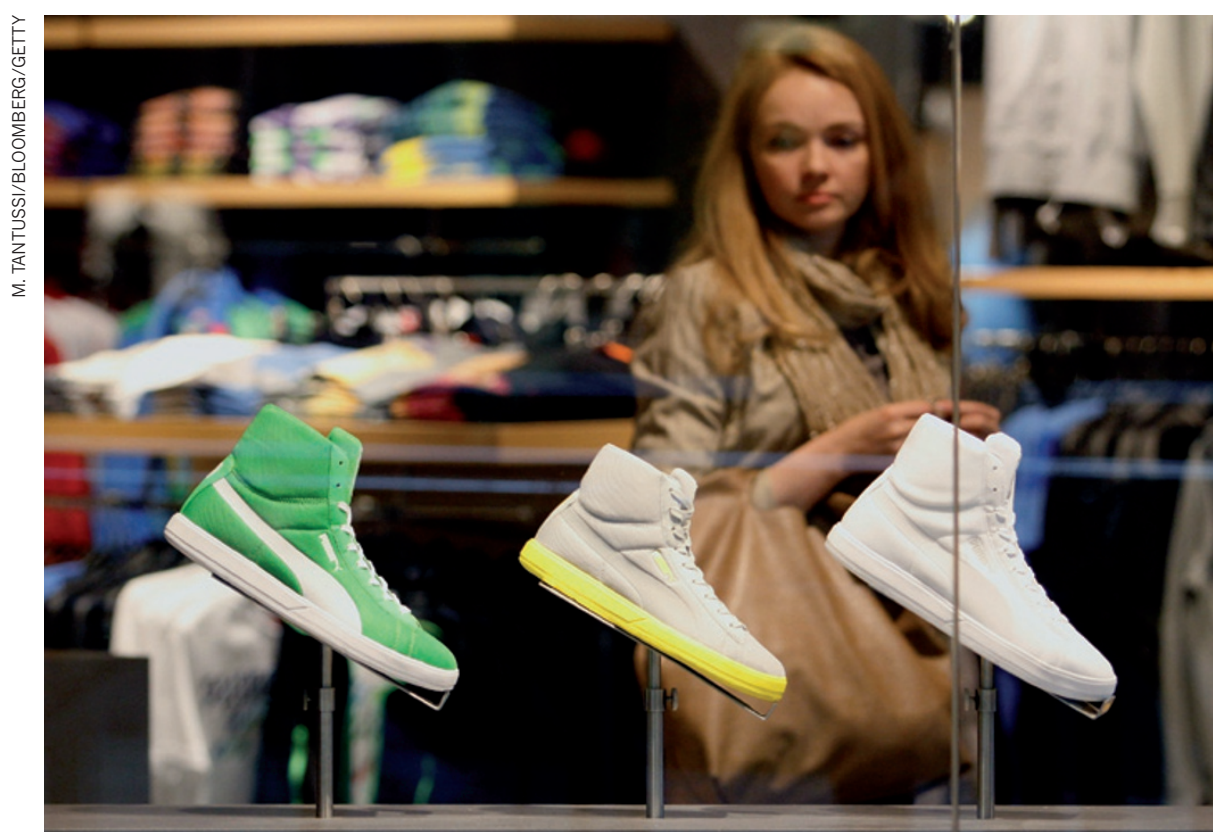

The shoe firm Puma has taken innovative steps towards disclosing its environmental impact.

\title{
The corporate climate overhaul
}

\section{The rules of business must be changed if the planet is to be saved, says Pavan Sukhdev.}

$\mathrm{T}$ here is an understandable tendency to put problems of the 'global commons' - climate change or biodiversity loss, for instance - in the hands of intergovernmental institutions. However, thus far these bodies have failed miserably. The United Nations Framework Convention on Climate Change (UNFCCC), born at the Earth Summit in Rio de Janeiro, Brazil, 20 years ago this month, has been unable to get its signatory governments to arrest greenhouse-gas emissions. And the Convention on Biological Diversity (the UNFCCC's non-identical twin, also born at that 1992 meeting) and its signatory governments have collectively failed to slow the loss of biodiversity.

These failures point to the need to recognize the key role of the private sector in determining economic direction and resource use globally. For effective climate-change or biodiversity solutions, members of the corporate world need to be brought to the table as ethical stewards of shared planetary resources, and not, as they have been so far, as self-interested exploiters of common wealth.

The private sector produces almost everything we consume, generating more than $60 \%$ of global gross domestic product (GDP) and employment. A study by the United Nations Environment Programme Finance Initiative $^{1}$ estimated that in 2008, annual corporate 'externalities' - the costs to society of the leading 3,000 public companies globally, in the form of emissions, freshwater use, pollution, waste and land-use change - added up to US\$2.15 trillion, or 3.6\% of global GDP. Two-thirds of this is due to the forecasted costs of climate-changing emissions. Such large costs to society of 'business as usual' show that today's corporation is, on average, an economic agent lacking in social purpose and focused on financial return to shareholders. Not surprisingly, it produces today's 'brown' economy, delivering private gains at the expense of public losses by increasing environmental risks and ecological scarcities.

Consumerism is often blamed, and consumers can indeed make crucial choices on the basis of how much material and energy is used for making, packaging and transporting goods. But on this road of economic choices, it

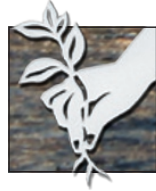

RETURN TO RIO

For Earth Summit news:

www.nature.com/rio20 is corporations, not consumers, in the driver's seat, and they are driving us in the wrong direction. Corporate advertising converts our insecurities into a chain of wants, needs and excessive demands, which have made our ecological footprint exceed the planet's ability to produce resources and absorb emissions by more than $50 \%$ (ref. 2 ).

Corporate lobbying often influences national policies to create advantage for particular industries or companies, to the detriment of the public good. Around $\$ 1$ trillion of harmful subsidies now support the brown economy, including more than $\$ 650$ billion in price and production subsidies for fossil fuels, and more than $\$ 300$ billion for mostly unsustainable agriculture and fisheries ${ }^{3}$. We are now consuming nature's capital, not its interest. And yet we have enshrined this corporate model in business law and practice, and, indeed, celebrated it as a crowning success of our times.

The rules of the game need to be changed, so that corporations can compete on the basis of innovation, resource conservation and satisfaction of multiple stakeholder demands - rather than on the basis of who is the most effective at influencing government regulation, avoiding taxes and obtaining subsidies for harmful activities in order to optimize shareholder returns. And those rules need to be changed quickly. The pace at which we are approaching the safe operating limits of our planetary systems ${ }^{4}$ suggests that a new corporate model must be ready to dominate economies by 2020 . Targeting 2050 or 2100 might be too late and, therefore, solely an academic exercise.

\section{EVOLUTIONARY CHANGE}

This new type of corporation, which I call Corporation 2020 (ref. 5 and www.corp2020. com), can still be profitable while contributing to a 'green economy': one that increases human well-being and social equity, and decreases environmental risks and ecological scarcities. Some examples show how this can work.

The German sportswear company Puma is leading the way in transparency and disclosure of its external costs to society. It measures, evaluates and publishes data on its carbon emissions, freshwater usage, pollution and waste. The unique aspect of this exercise is that Puma has measured and monetized these impacts, calculating them along its entire supply chain. It has effectively created the world's first environmental profit-andloss statement. Although Puma disclosed an estimated $€ 145$ million (US\$182 million) in such externalities for 2010, the revelation was far from the public-relations disaster that some had predicted. The firm is now using what it learned to engage its raw materials and manufacturing supply chain (which is where almost $95 \%$ of these externalities arise) to 
- improve its environmental performance.

A true Corporation 2020 must not only measure and minimize negative externalities, but also actively create positive externalities. A good example of a future-thinking company in this regard is Infosys, an information-technology giant based in India, which is a veritable factory of 'human capital'. Infosys's campus in Mysore has the astonishing capacity to provide the equivalent of a bachelor's degree in computer science to 14,000 employees at a time. It is no coincidence that the firm receives more than one million job applications a year, has an exceptionally talented cadre of professionals and has compounded sales and earnings growth that averages $70 \%$.

In addition to building human capital, a Corporation 2020 must build 'social capital'. Traditional types of community - villages and neighbourhoods - are no longer able to fulfil the human need for social ties. Competition, labour mobility and a culture of long working hours have taken a toll on people's ability to build strong connections where they live. Corporations can be part of the solution to rebuild these networks. An iconic example in the United States is the corporate headquarters of Google in Mountain View, California. By encouraging a sense of community and providing benefits such as gourmet food, laundry services and recreational activities, Google has created a culture in which employees feel proud and energized to come to work.

Forward-looking behaviour tends to be found mostly in companies that have foreseen that providing a benefit to society can also benefit themselves. However, not every desired behaviour of a Corporation 2020 is justifiable purely on the basis of self-interest. Good companies have to swim against the current of perverse taxes and subsidies, competition that cuts corners by hiding costs, and a legal history that supports slavish devotion to maximizing shareholder value. Significant changes in the operating environment for business will be necessary if the corporate world is to move to a green economy.

\section{FOUR SOLUTIONS}

Just as a biological species evolves in response to the natural environment and in turn influences its environment, today's corporation can evolve into Corporation 2020 if it has the right regulatory environment. But four vital planks of change must be put in place with urgency.

The first is disclosure of externalities. This will provide the missing information needed by corporate managers, governments, civil society, consumers and investors to differentiate their responses to different corporations. There are many financial reporting agencies around the globe, including the International Accounting Standards Board, the US Financial Accounting Standards Board and the UK Institute of Chartered Accountants of England and Wales, the rules of which require that corporations submit annual financial reports. These bodies should commission research and develop methodologies for measuring the most material corporate environmental externalities, as well as those from human and social capital. These externalities should also be disclosed in statutory annual reports. capital $^{6}$. Excessive leverage has been the key driver of most major global recessions - the Latin American debt crisis of the 1980s, the US savings and loans crisis of the 1980s and 1990s, the 1997 Asian debt crisis and the recent mortgages crisis. Recessions, in turn, increase poverty and reduce social equity, acting against a crucial objective of a green economy. Corporations that are 'too big to fail', which effectively have recourse to public funds in times of crisis, now include not just banks but also insurers, mortgage lenders, car-makers, airlines and even hedge funds.

This cannot be a recipe for economic sustainability. G20 governments and central banks should monitor and limit the leverage of major corporations.

The fourth plank is resource taxation. The tax authorities of G20 governments should implement changes in the life-cycle incidence of taxation: more tax should be charged at the point of resource extraction (such as the mining of fossil fuels and minerals) rather than at the point of sale or the point of profit reporting. This will encourage efficient use of materials rather than more mining, more product and packaging and more waste. Sadly, a serious effort of this kind in Australia - an attempt to increase resource taxation in August 2010 - led to an avalanche of lobbying and advertising by mining companies that was so successful that it unseated Prime Minister Kevin Rudd, the main architect of the tax. Some may remember Rudd as the leader behind Australia's signature to the Kyoto Protocol. Although the tax will still be introduced, it has been greatly watered down.

The problems caused by today's corporate structure are complex. They require complex solutions, which can only be delivered through collaboration on a global scale, across a diversity of sectors and through at least these four major planks of change. Humanity has so far been neither willing nor able to engage in this manner. Yet engage we must, and we must begin now. The reward is unsurpassed: a sustainable economy, on a habitable planet.

Pavan Sukhdev is the chief executive of the environmental consulting firm GIST Advisory, and served as head of the United Nations Environment Programme's Green Economy initiative from 2008 to 2011. e-mail:pavan@corp2020.com

1. Principles for Responsible Investment and UNEP Finance Initiative Universal Ownership: Why Environmental Externalities Matter to Institutional Investors (Trucost, 2010).

2. WWF Living Planet Report 2012 (WWF, 2012)

3. UNEP Towards a Green Economy: Pathways to Sustainable Development and Poverty Eradication (United Nations Environment Programme, 2011).

4. Rockström, J. et al. Ecol. Soc. 14, 32 (2009).

5. Sukhdev, P. Corporation 2020: Transforming Business for Tomorrow's World (Island, in the press). 6. Geanakoplos, J. Nature 457, 963 (2009). 